\title{
The Association Between Hyperlipidemia and In-Hospital Outcomes in Takotsubo Cardiomyopathy
}

This article was published in the following Dove Press journal: Diabetes, Metabolic Syndrome and Obesity: Targets and Therapy

\author{
Pengyang $\mathrm{Li}^{1, *}$ \\ Xiaojia $\mathrm{Lu}^{2, *}$ \\ Catherine Teng $\mathbb{1}^{3}$ \\ Michelle Hadley ${ }^{4}$ \\ Peng $\mathrm{Cai}^{5}$ \\ Qiying Dai ${ }^{5}$ \\ Bin Wang $\mathbb{D}^{2,6}$
}

'Department of Medicine, Saint Vincent Hospital, Worcester, MA 0I608, USA;

${ }^{2}$ Department of Cardiology, The First Affiliated Hospital of Shantou University Medical College, Shantou, Guangdong 5I504I, People's Republic of China; ${ }^{3}$ Department of Medicine, Yale New Haven Health-Greenwich Hospital, Greenwich, CT 06830, USA; ${ }^{4}$ Division of Cardiology, Saint Vincent Hospital, Worcester, MA 01608, USA;

${ }^{5}$ Department of Mathematical Sciences, Worcester Polytechnic Institute,

Worcester, MA 01609, USA; ${ }^{6}$ Clinical Research Center, The First Affiliated Hospital of Shantou University Medical College, Shantou, Guangdong 51504I,

People's Republic of China

*These authors contributed equally to this work

Correspondence: Bin Wang Department of Cardiology, The First Affiliated Hospital of Shantou University Medical College, 57 Changping Road,

Shantou, Guangdong 51504I, People's Republic of China

Tel +86-75488905399

Fax +8675488259850

Email wangbin_pku@।26.com
Purpose: Hyperlipidemia (HLD) is one of the most common cardiovascular risk factors and is prevalent in patients with takotsubo cardiomyopathy (TCM), but the association between HLD and TCM patients' outcomes is unclear. We investigated the impact of HLD on the inhospital outcomes of TCM patients.

Patients and Methods: Our retrospective cohort study used the latest available data from the National Inpatient Sample (2016-2017). Using the ICD-10 code, we identified 3139 patients with a primary diagnosis of TCM, 1530 of whom had HLD. We compared inhospital outcomes between HLD and non-HLD groups before and after propensity score matching.

Results: In the unmatched cohort, the HLD group had lower incidences of cardiac arrest, cardiogenic shock, and acute respiratory failure (ARF); shorter length of stay (LOS); and lower total charges $(A l l p<0.05)$. In-hospital mortality $(p=0.102)$ and ventricular arrhythmia $(p=0.235)$ rates did not differ. After propensity score matching, the HLD group had lower rates of in-hospital mortality $(1.1 \%$ vs $2.4 \%, \mathrm{p}=0.027)$, ARF $(9.1 \%$ vs $12.1 \%, \mathrm{p}=0.022)$ and cardiogenic shock $(3.4 \%$ vs $5.6 \%, \mathrm{p}=0.012)$, shorter $\operatorname{LOS}(3.20 \pm 3.27$ days vs $3.57 \pm 3.14$ days, $\mathrm{p}=0.005)$, and lower total charges $(\mathrm{p}=0.013)$. The matched groups did not differ significantly regarding cardiac arrest $(p=0.141)$, ventricular arrhythmia $(p=0.662)$ or acute kidney injury $(\mathrm{AKI})(\mathrm{p}=0.167)$.

Conclusion: Counterintuitively, HLD was associated with better in-hospital outcomes in both the unmatched and propensity-matched cohorts of hospitalized TCM patients. Further studies are needed to investigate the mechanisms that may contribute to the association in TCM patients with HLD.

Keywords: takotsubo cardiomyopathy, hyperlipidemia, mortality

\section{Introduction}

Since the diagnosis of takotsubo cardiomyopathy (TCM) was introduced in the $1990 \mathrm{~s},{ }^{1}$ there is much yet to be discovered about the disease. TCM is more prevalent among females, occurring around 10 times more often in females than males, ${ }^{2}$ and has similar clinical features to ACS, including typical ischemic chest pain, typical troponin and ECG changes. ${ }^{3}$ Once thought a rare and benign diagnosis (due to its self-limiting clinical course ${ }^{4,5}$ ), TCM, characterized by acute left ventricular systolic dysfunction without acute coronary artery obstruction, is increasingly recognized ${ }^{6,7}$ as having a substantial risk of mortality, similar to acute coronary syndrome (ACS). ${ }^{8}$ 
Hyperlipidemia (HLD) is a common metabolic disease in the United States, afflicting about $33.5 \%$ adults over age 20. ${ }^{9}$ HLD is characterized by high levels of low-density lipoprotein cholesterol (LDL-C) or high triglycerides (TG), and plays an important role in the pathogenesis of cardiovascular diseases. ${ }^{10,11}$ Previous studies have found that HLD was prevalent in TCM patients ${ }^{12-14}$ - a study by Summers et al investigating the risk factors of TCM found that $52 \%$ of TCM patients had HLD. ${ }^{12}$

In studying HLD's associations with in-hospital outcomes of cardiovascular disease, ${ }^{15-17}$ findings counterintuitively suggest that low serum cholesterol level has a negative association with short-term outcomes. In Reddy et al's study, lower levels of LDL-C were associated with a higher in-hospital mortality in patients with acute myocardial infarction. ${ }^{16}$ Another study indicated that patients with lower levels of total cholesterol were associated with higher in-hospital mortality in acute heart failure patients. ${ }^{17}$ While one study found the HLD did not affect the long-term mortality with TCM patients, ${ }^{18}$ the impact of HLD on the short-term outcomes of TCM patients has yet to be reviewed.

In this study, we sought to identify the association between HLD and the in-hospital outcomes among patients who were admitted for TCM using the latest available data from the National Inpatient Sample (NIS).

\section{Method}

\section{Data Source}

The NIS database is a stratified sample of $20 \%$ of all inpatient hospitalizations in the United States that includes data from $>7$ million unweighted and an estimated $>35$ million weighted hospital stays each year. ${ }^{19}$ The NIS database has been extensively used in many fields and it has the advantage of large sample sizes, and it contains patient characteristics such as a primary diagnosis for admission, comorbidities, and detailed patient demographics. As the information on NIS is de-identified, our study did not require the Institutional Review Board's approval. All comorbidities and inpatient complications are selected by the International Classification of Diseases, Tenth Revision, Clinical Modification (ICD-10$\mathrm{CM}$ ) coding system from the NIS database. Patients admitted with HLD were identified by using ICD-10-CM codes E78.0-E78.5, which were consistent with the methodology used in previous studies. ${ }^{20}$ The ICD-10-CM codes used in this study are shown in Table 1.
Table I International Classification of Disease, I0th Edition, Clinical Modification (ICD-I0-CM) Codes Used for Comorbidities and Complications

\begin{tabular}{|c|c|}
\hline $\begin{array}{l}\text { Comorbidities/ } \\
\text { Complications }\end{array}$ & ICD-I0 Code \\
\hline $\begin{array}{l}\text { TCM } \\
\text { HLD }\end{array}$ & $\begin{array}{l}\text { I5I8I } \\
\text { E780-E785 }\end{array}$ \\
\hline $\begin{array}{l}\text { Comorbidities } \\
\text { Smoking } \\
\text { Hypertension } \\
\text { DM } \\
\text { Obesity } \\
\text { Anxiety } \\
\text { Depression } \\
\text { COPD } \\
\text { OSA } \\
\text { CKD } \\
\text { PAD } \\
\text { Sepsis }\end{array}$ & $\begin{array}{l}\text { FI7-FI7299, Z720, Z8789I } \\
\text { IIO, II5-II59 } \\
\text { EI0-EI09, EII-EII9, EI3-EI39 } \\
\text { Z683-Z6839, Z684-Z6845, E66-E669 } \\
\text { F064, F40-F409, F4I-F4I9 } \\
\text { F32-F329, F33-F339, F34I } \\
\text { J4I-J4I8, J42, J43-J439, J44-J449 } \\
\text { G473-G4739 } \\
\text { NI8-NI89 } \\
\text { I70, I7I, I72, I73, I74, I77 } \\
\text { A02I, A227, A267, A327, A40-A409, A4I- } \\
\text { A4I9, A427, A5486, B377, O0337, O0387, } \\
\text { O0487, O0737, O0882, O85, P36-P369, } \\
\text { R652-R652I }\end{array}$ \\
\hline $\begin{array}{l}\text { Complications } \\
\text { Cardiac arrest } \\
\text { Cardiogenic shock } \\
\text { Ventricular } \\
\text { arrhythmia } \\
\text { AKI } \\
\text { ARF }\end{array}$ & $\begin{array}{l}146-1469 \\
\text { R570 } \\
1472,1490-14902 \\
\text { NI7-NI79 } \\
\text { J960-J9622 }\end{array}$ \\
\hline
\end{tabular}

Abbreviations: AKI, acute kidney injury; ARF, acute respiratory failure; CKD, chronic kidney disease; COPD, chronic obstructive pulmonary disease; DM, diabetes mellitus; HLD, hyperlipidemia; OSA, obstructive sleep apnea; PAD, peripheral artery disease; TCM, takotsubo cardiomyopathy.

\section{Study Population}

Using the ICD-10-CM code of I5181, we selected patients with a primary diagnosis of TCM from January 1, 2016, to December 31, 2017. Patients without discharge status were excluded. The patient selection process in this study is shown in Figure 1.

\section{Variables}

The variables in our study include patient demographics (age, sex, race, household income, primary payer for the hospitalization) and hospital demographics (hospital type, hospital size and region). To further reduce selection bias, we included common cardiovascular comorbidities, such as smoking, hypertension, obstructive sleep apnea (OSA), peripheral artery disease (PAD), and other reported risk factors for TCM including chronic obstructive pulmonary disease (COPD), ${ }^{21,22}$ anxiety ${ }^{23}$ and depressive disorders, ${ }^{18}$ 
National Inpatient Sample Database (2016-2017)

$$
(\mathrm{N}=14,294,784)
$$

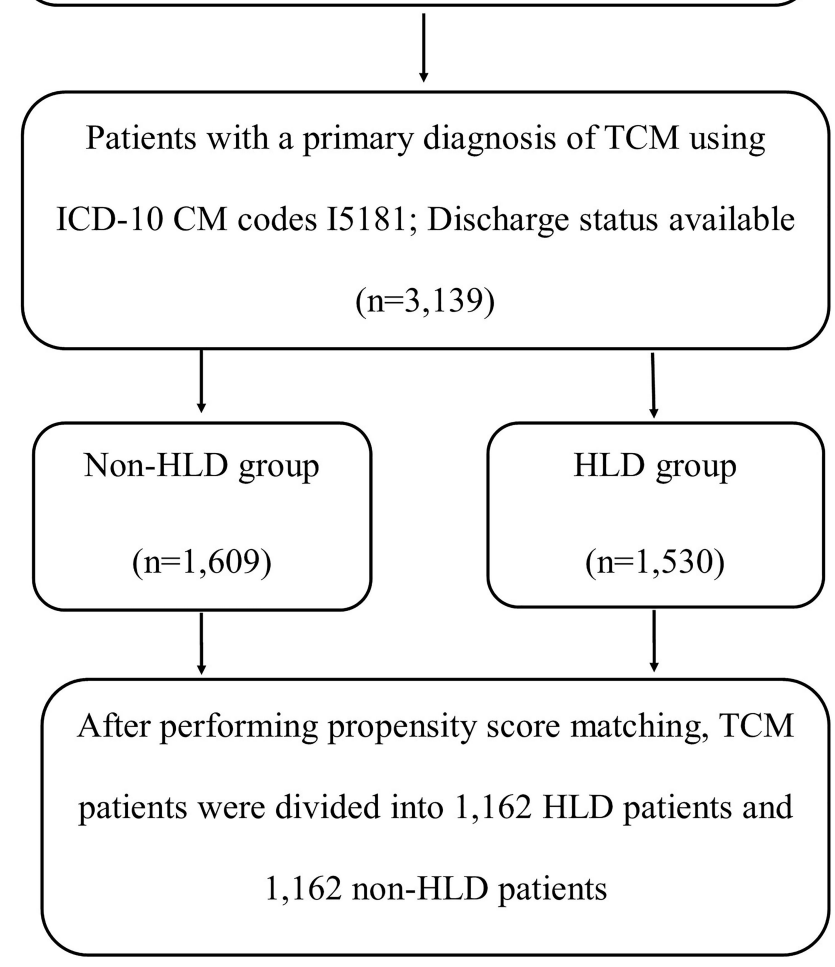

Figure I Flow chart of the selection process for the final patient sample used in this study.

Notes: Inclusion criteria were applied to the National Inpatient Sample 2016 and 2017 database. All eligible patients were matched I:I based on propensity scoring to generate the HLD versus non-HLD comparison cohorts.

Abbreviations: HLD, hyperlipidemia; ICD-I0-CM codes, International Classification of Disease, I0th edition, Clinical Modification codes; TCM, takotsubo cardiomyopathy.

obesity, ${ }^{24}$ diabetes mellitus (DM) ${ }^{25}$ chronic kidney disease $(\mathrm{CKD})^{26}$ and sepsis. ${ }^{27}$

\section{In-Hospital Outcomes}

The primary outcomes of our study were in-hospital mortality, length of stay (LOS) and total hospital charges. We also examined in-hospital complications including cardiac arrest, cardiogenic shock, ventricular arrhythmia, acute kidney injury (AKI), and acute respiratory failure (ARF).

\section{Statistical Analysis}

Continuous variables were expressed as a mean with standard deviation (SD) and were tested with a $t$-test, while categorical variables were expressed as percentages and tested with a chi-square test. We compared patients admitted for TCM with HLD and those without HLD prior to and after propensity score matching. The characteristics we selected to adjust for comparison were age, sex, race, and cardiovascular risk factors as described above.

We identified 3139 patients with a primary diagnosis of TCM with available discharge status by ICD-10 code. Based on whether the patient had a comorbidity of HLD, we divided patients with a primary diagnosis of TCM into two groups: one with documented comorbidity of HLD, the other one without. There are 1530 and 1609 patients in the HLD group and non-HLD group, respectively. Both groups had 1162 patients after propensity score matching.

The propensity score matching model was used to match selected baseline characteristics. Both groups of patients were matched into each group in a 1:1 target ratio. Finally, we compared the in-hospital outcomes between the two groups prior to and after adjustment. Differences were considered statistically significant if $p<$ 0.05. All statistical analyses were performed by the R statistics software (version 3.6.1, R Development Core Team).

\section{Results \\ Baseline Characteristics}

Prior to matching, patients in the HLD group were older $(68.71 \pm 11.04$ vs $64.73 \pm 13.80, \mathrm{p}<0.001)$ compared to the non-HLD group. The HLD group had a higher proportion of certain comorbidities, such as hypertension (57.6\% vs $40.8 \%, \mathrm{p}<0.001)$, DM (27.5\% vs $12.6 \%, \mathrm{p}<0.001)$, obesity ( $15.4 \%$ vs $10.1 \%, \mathrm{p}<0.001)$, depressive disorders $(20.1 \%$ vs $15.4 \%, \mathrm{p}=0.001)$, OSA $(7.1 \%$ vs $3.9 \%$, p < $0.001)$, CKD (10.7\% vs $6.8 \%, \mathrm{p}<0.001)$ and PAD $(8.8 \%$ vs $5.0 \%, \mathrm{p}<0.001)$. After propensity score matching, the baseline characteristics were comparable $(p>0.05)$. Details of baseline characteristics of patients are shown in Table 2. We used standardized mean difference to examine the balance of the covariate distribution between HLD group and non-HLD group. After propensity score matching, all standardized mean difference is less than 0.1 between matched cohorts ${ }^{28}$ (Figure 2).

\section{In-Hospital Mortality, Length of Stay, and Total Charges}

Prior to propensity score matching, there was no statistical difference in in-hospital mortality between the two groups. We found that HLD patients had a shorter LOS (3.26 \pm 3.17 days vs $3.60 \pm 3.46$ days, $\mathrm{p}=0.004$ ) and lower total 
Table 2 Baseline Characteristics

\begin{tabular}{|c|c|c|c|c|c|c|}
\hline \multirow[t]{2}{*}{ Variables } & \multicolumn{3}{|c|}{ Unmatched Cohort } & \multicolumn{3}{|c|}{ Propensity-Matched Cohort } \\
\hline & $\begin{array}{l}\text { TCM without } \\
\text { HLD }\end{array}$ & $\begin{array}{l}\text { TCM with } \\
\text { HLD }\end{array}$ & $P$ value & $\begin{array}{l}\text { TCM without } \\
\text { HLD }\end{array}$ & $\begin{array}{l}\text { TCM with } \\
\text { HLD }\end{array}$ & $P$ value \\
\hline $\mathbf{n}$ & 1609 & 1530 & & 1162 & 1162 & \\
\hline Age, (mean (sd)) & $64.73(13.80)$ & $68.71(11.04)$ & $<0.001$ & $67.63(12.68)$ & $67.46(11.00)$ & 0.719 \\
\hline $\begin{array}{l}\text { Sex, n (\%) } \\
\text { Male } \\
\text { Female } \\
\text { Unknown }\end{array}$ & $\begin{array}{l}163(10.1) \\
1444(89.7) \\
2(0.1)\end{array}$ & $\begin{array}{l}\text { I35 (8.8) } \\
1395(91.2) \\
0(0.0)\end{array}$ & 0.175 & $\begin{array}{l}100(8.6) \\
1062(91.4) \\
0(0.0)\end{array}$ & $\begin{array}{l}100(8.6) \\
1062(91.4) \\
0(0.0)\end{array}$ & I \\
\hline $\begin{array}{l}\text { Race, } \mathbf{n}(\%) \\
\text { White } \\
\text { Black } \\
\text { Hispanic } \\
\text { Asian/Pacific Islander } \\
\text { Native American } \\
\text { Other } \\
\text { Unknown }\end{array}$ & $\begin{array}{l}1259(78.2) \\
106(6.6) \\
100(6.2) \\
22(1.4) \\
14(0.9) \\
35(2.2) \\
73(4.5)\end{array}$ & $\begin{array}{l}1235(80.7) \\
100(6.5) \\
76(5.0) \\
23(1.5) \\
4(0.3) \\
32(2.1) \\
60(3.9)\end{array}$ & 0.192 & $\begin{array}{l}930(80.0) \\
67(5.8) \\
67(5.8) \\
17(1.5) \\
4(0.3) \\
26(2.2) \\
51(4.4)\end{array}$ & $\begin{array}{l}950(81.8) \\
70(6.0) \\
60(5.2) \\
17(1.5) \\
4(0.3) \\
20(1.7) \\
41(3.5)\end{array}$ & 0.865 \\
\hline $\begin{array}{l}\text { Patient location, } \mathbf{n}(\%) \\
\text { "Central" counties of metro areas of }\end{array}$ & $367(22.8)$ & $354(23.1)$ & 0.539 & $273(23.5)$ & $263(22.6)$ & 0.996 \\
\hline $\begin{array}{l}\text { "Finge" counties of metro areas of } \geq 1 \text { million } \\
\text { population }\end{array}$ & $370(23.0)$ & $394(25.8)$ & & $280(24.1)$ & $292(25.1)$ & \\
\hline $\begin{array}{l}\text { Counties in metro areas of } 250,000-999,999 \\
\text { population }\end{array}$ & $4 I I(25.5)$ & $357(23.3)$ & & $279(24.0)$ & $278(23.9)$ & \\
\hline $\begin{array}{l}\text { Counties in metro areas of 50,000-249,999 } \\
\text { population }\end{array}$ & $168(10.4)$ & $158(10.3)$ & & $122(10.5)$ & $120(10.3)$ & \\
\hline Micropolitan counties & $165(10.3)$ & $156(10.2)$ & & $12 \mid(10.4)$ & $122(10.5)$ & \\
\hline Non metropolitan or micropolitan counties & $12 \mid(7.5)$ & $107(7.0)$ & & $84(7.2)$ & $83(7.1)$ & \\
\hline NA & $7(0.4)$ & $4(0.3)$ & & $3(0.3)$ & $4(0.3)$ & \\
\hline Mean household income, n (\%) & & & 0.198 & & & 0.809 \\
\hline$\$ 1-\$ 42,999$ & $401(24.9)$ & $348(22.7)$ & & $276(23.8)$ & $270(23.2)$ & \\
\hline$\$ 43,000-\$ 53,999$ & $429(26.7)$ & $384(25.1)$ & & $311(26.8)$ & $292(25.1)$ & \\
\hline$\$ 54,000-\$ 70,999$ & $406(25.2)$ & $432(28.2)$ & & $296(25.5)$ & $320(27.5)$ & \\
\hline$\$ 71,000$ or more & $351(21.8)$ & $350(22.9)$ & & $265(22.8)$ & $266(22.9)$ & \\
\hline Unknown & $22(1.4)$ & $16(1.0)$ & & $14(1.2)$ & $14(1.2)$ & \\
\hline Primary payer, n (\%) & & & $<0.001$ & & & 0.998 \\
\hline Medicare & $858(53.3)$ & $1009(65.9)$ & & $7 \mid 5(6 \mid .5)$ & $718(61.8)$ & \\
\hline Medicaid & $175(10.9)$ & $99(6.5)$ & & $86(7.4)$ & $88(7.6)$ & \\
\hline Private including $\mathrm{HMO}$ & $46 I(28.7)$ & $367(24.0)$ & & $312(26.9)$ & $304(26.2)$ & \\
\hline Self-pay & $71(4.4)$ & $30(2.0)$ & & $29(2.5)$ & $30(2.6)$ & \\
\hline No charge & $5(0.3)$ & $I(0.1)$ & & $I(0.1)$ & $I(0.1)$ & \\
\hline Other & $39(2.4)$ & $23(1.5)$ & & $19(1.6)$ & $21(1.8)$ & \\
\hline Unknown & $0(0.0)$ & $\mathrm{I}(0 . \mathrm{I})$ & & $0(0.0)$ & $0(0.0)$ & \\
\hline Hospital type, n (\%) & & & 0.438 & & & 0.863 \\
\hline Rural & $96(6.0)$ & $78(5.1)$ & & $69(5.9)$ & $64(5.5)$ & \\
\hline Urban non-teaching & $36 \mathrm{I}(22.4)$ & $363(23.7)$ & & $277(23.8)$ & $272(23.4)$ & \\
\hline Urban teaching & $1152(71.6)$ & $1089(71.2)$ & & $816(70.2)$ & $826(7 I .1)$ & \\
\hline
\end{tabular}

(Continued) 
Table 2 (Continued).

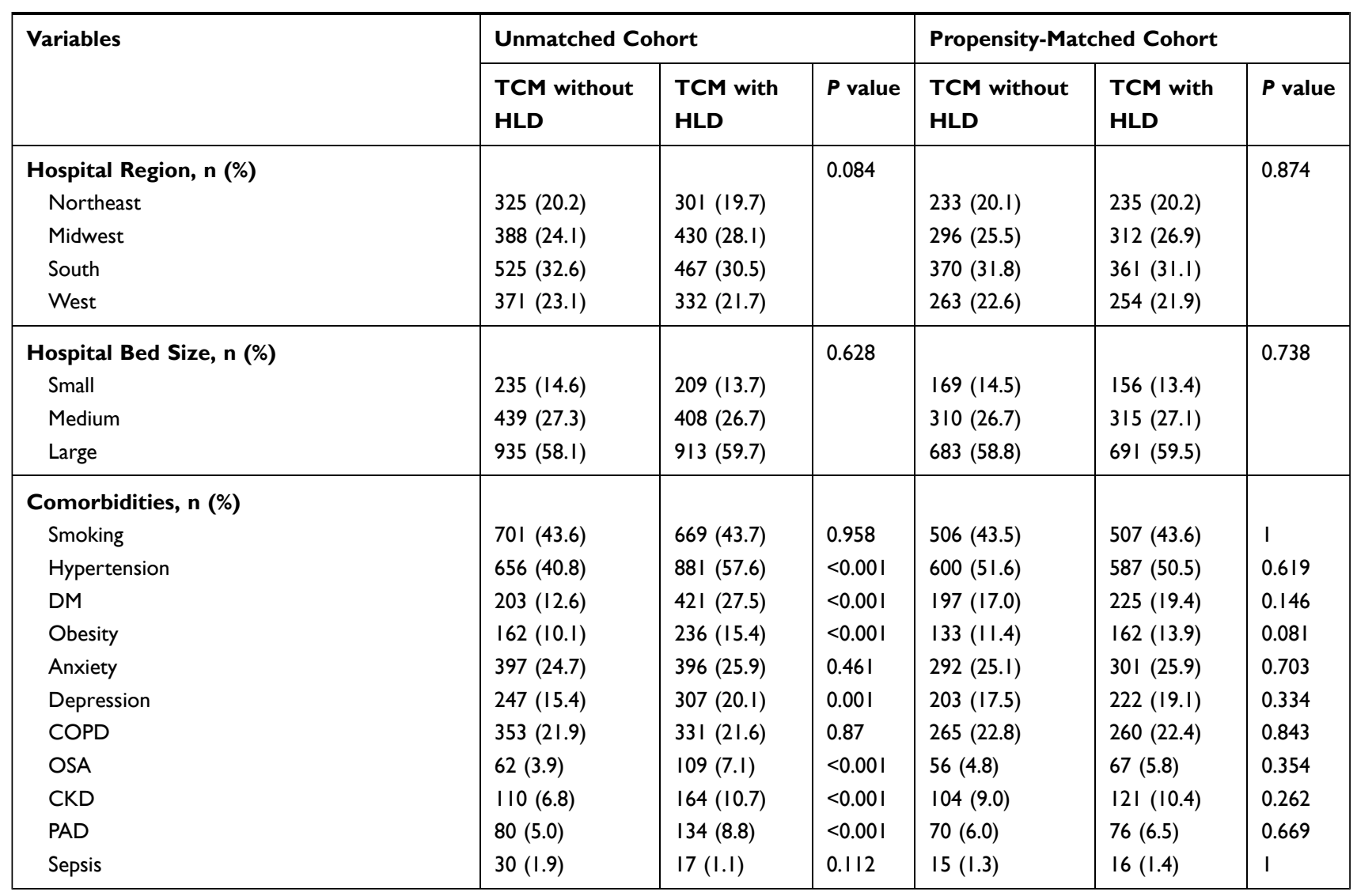

Abbreviations: CKD, chronic kidney disease; COPD, chronic obstructive pulmonary disease; DM, diabetes mellitus; HLD, hyperlipidemia; OSA, obstructive sleep apnea; PAD, peripheral artery disease; TCM, takotsubo cardiomyopathy.

charges of stay (US\$ 47,048.09 $\pm 40,379.55$ vs US\$ $52,478.42 \pm 54,067.55, \mathrm{p}=0.002)$ compared to TCM patients without HLD (Table 3).

After propensity score matching, we found that the inhospital mortality rate was lower in HLD group $(1.1 \%$ vs $2.4 \%, \mathrm{p}=0.027$; OR $0.46,95 \%$ CI $0.24-0.89$ ). (Figure 3 ) HLD group has shorter LOS $(3.20 \pm 3.27$ days vs $3.57 \pm$ 3.14 days, $p=0.005$ ) and less total charges of stay (US\$ $46,825.87 \pm 39,620.81$ vs US\$ $51,282.36 \pm 46,190.15, p=$ 0.013 ) (Table 3).

\section{In-Hospital Complications}

We found that the HLD group had a lower incidence of in-hospital complications, including cardiac arrest $(1.2 \%$ vs $2.3 \%, p=0.035)$, cardiogenic shock $(3.5 \%$ vs $5.7 \%, \mathrm{p}=0.006)$ and $\operatorname{ARF}(9.3 \%$ vs $12.4 \%, \mathrm{p}=$ 0.006) in unmatched cohorts. There was no statistical significance when comparing the outcomes of ventricular arrhythmias and AKI between the two groups.
After propensity score matching, the HLD group had lower incidence of cardiogenic shock $(3.4 \%$ vs $5.6 \%$, p $=$ 0.012 ; OR $0.59,95 \%$ CI $0.39-0.88$ ) and ARF (9.1\% vs $12.1 \%, \mathrm{p}=0.022$; OR $0.73,95 \%$ CI $0.56-0.95)$. The details of the result can be found in Table 3 and Figure 3.

\section{Discussion}

To our knowledge, this is the first study to examine the association between HLD and the short-term outcomes of patients being admitted to hospital for TCM. We found that patients who carried a diagnosis of HLD and were admitted for TCM were associated with lower in-hospital mortality rate, shorter LOS, lower total charges of stay and lower rate of cardiogenic shock.

Similar to previous studies, we found that HLD was common among TCM patients, with $48.7 \%$ of them carrying a diagnosis of HLD. ${ }^{12-14}$ Though the pathophysiology of TCM is not well understood, endothelial dysfunction is one of the well-accepted hypotheses. ${ }^{29,30}$ HLD is known to cause 


\section{Covariate Balance}

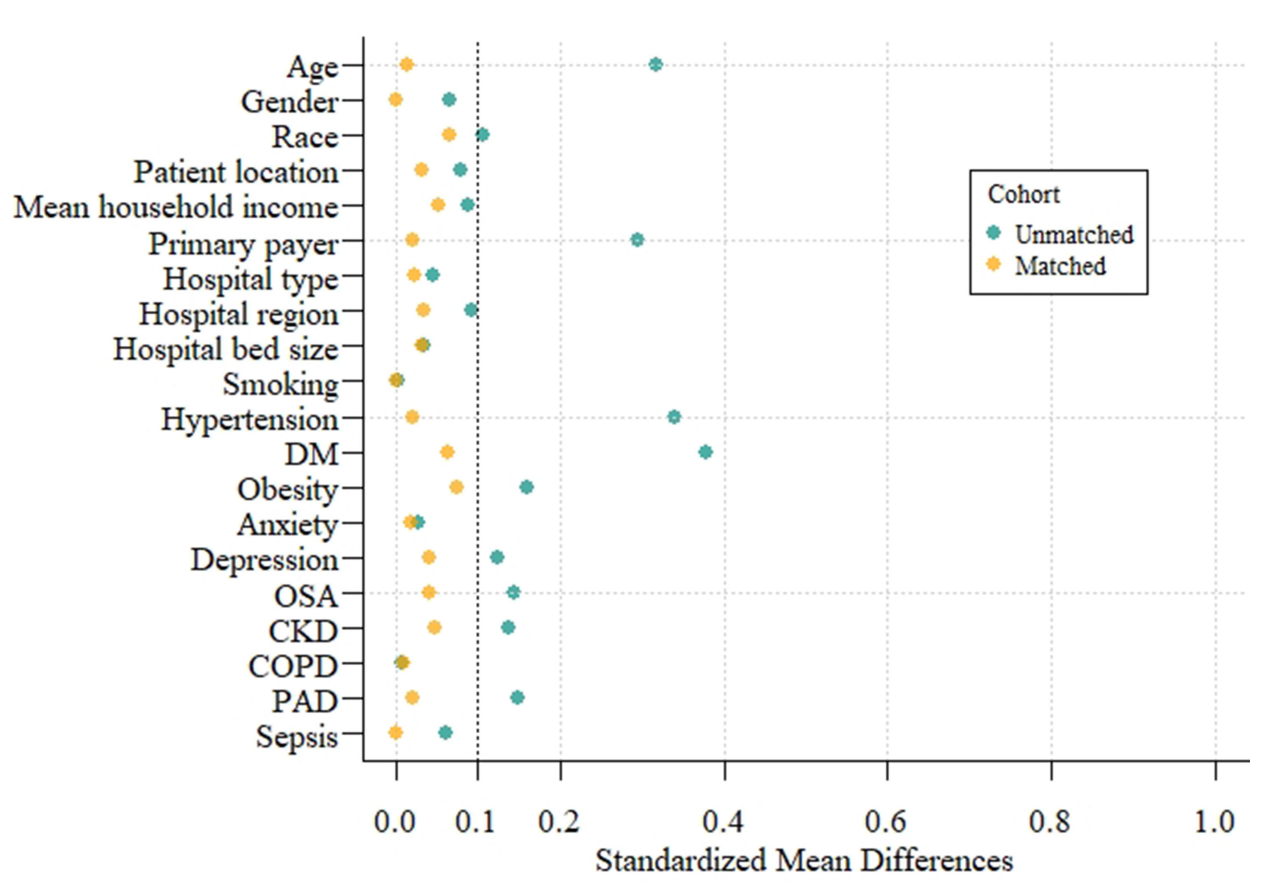

Figure 2 Standardized mean differences of covariates before and after propensity score matching between TCM patients with and without HLD. Abbreviations: CKD, chronic kidney disease; COPD, chronic obstructive pulmonary disease; DM, diabetes mellitus; HLD, hyperlipidemia; OSA, obstructive sleep apnea; PAD, peripheral artery disease; TCM, takotsubo cardiomyopathy.

endothelial dysfunction as a result of an elevated oxidized LDL-C (ox-LDL) level. Ox-LDL can damage vascular endothelium by 1) downregulating Hippo Yes-associated protein/YLP motif contain 1 (Hippo-YAP/ZAP) pathway which in turn interferes with cardiovascular remodeling, ${ }^{31}$ 2) by inducing the apoptosis of vascular endothelial as a result of upregulated expression of autophagy-related protein, ${ }^{32}$ and 3) by inhibiting vascular relaxations induced by nitric oxide. ${ }^{33}$ In theory, HLD patients are more likely to have endothelial dysfunction, which may facilitate the pathophysiologic basis for the occurrence of TCM.

Interestingly, our study found TCM patients with HLD had paradoxically better in-hospital outcomes than those without HLD - which parallels the previous findings in other cardiovascular diseases such as acute myocardial infarction $^{34-36}$ and heart failure. ${ }^{37,38}$ Studies have suggested that patients with myocardial infarction with higher cholesterol and TG levels were associated with better

Table 3 In-Hospital Outcomes Before and After Propensity Score Matching

\begin{tabular}{|c|c|c|c|c|c|c|}
\hline \multirow[t]{2}{*}{ Variables } & \multicolumn{3}{|l|}{ Unmatched Cohort } & \multicolumn{3}{|c|}{ Propensity-Matched Cohort } \\
\hline & TCM without HLD & TCM with HLD & $P$ value & TCM without HLD & TCM with HLD & $P$ value \\
\hline n & 1609 & 1530 & & 1162 & 1162 & \\
\hline \multicolumn{7}{|l|}{ Outcomes } \\
\hline Death, n (\%) & $33(2.1)$ & $19(1.2)$ & 0.102 & $28(2.4)$ & $13(1.1)$ & 0.027 \\
\hline Cardiac arrest, n (\%) & $37(2.3)$ & $19(1.2)$ & 0.035 & $24(2.1)$ & $14(1.2)$ & 0.141 \\
\hline Cardiogenic shock, n (\%) & $91(5.7)$ & $54(3.5)$ & 0.006 & $65(5.6)$ & $39(3.4)$ & 0.012 \\
\hline Ventricular arrhythmia & $70(4.4)$ & $53(3.5)$ & 0.235 & $46(4.0)$ & $4 \mid(3.5)$ & 0.662 \\
\hline $\mathrm{AKI}, \mathrm{n}(\%)$ & $146(9.1)$ & $|4|(9.2)$ & 0.940 & $114(9.8)$ & $94(8.1)$ & 0.167 \\
\hline ARF, n (\%) & $200(12.4)$ & $142(9.3)$ & 0.006 & $14 \mid(12.1)$ & $106(9.1)$ & 0.022 \\
\hline LOS, (mean (sd)) & $3.60(3.46)$ & $3.26(3.17)$ & 0.004 & $3.57(3.14)$ & $3.20(3.27)$ & 0.005 \\
\hline Total charge (mean (sd)) & $52,478.42(54,067.55)$ & $47,048.09(40,379.55)$ & 0.002 & $51,282.36(46,190.15)$ & $46,825.87(39,620.81)$ & 0.013 \\
\hline
\end{tabular}

Abbreviations: AKI, acute kidney injury; ARF, acute respiratory failure; HLD, hyperlipidemia; LOS, length of stay; TCM, takotsubo cardiomyopathy. 


\begin{tabular}{|c|c|c|c|c|c|}
\hline Outcomes & $\begin{array}{c}\text { Odds Ratio } \\
\text { 95\% C.I. }\end{array}$ & & $\begin{array}{c}\text { Odds (\%) } \\
\text { without Hyperlipidemia }\end{array}$ & $\begin{array}{c}\text { Odds (\%) } \\
\text { with Hyperlipidemia }\end{array}$ & P-values \\
\hline Death & $0.46(0.24,0.89)$ & $\longrightarrow$ & 2.47 & 1.13 & 0.03 \\
\hline Cardiogenic shock & $0.59(0.39,0.88)$ & $\rightarrow$ & 5.93 & 3.47 & 0.01 \\
\hline Cardiac arrest & $0.58(0.3,1.12)$ & $\rightarrow$ & 2.11 & 1.22 & 0.14 \\
\hline Ventricular arrhythmia & $0.89(0.58,1.36)$ & $\rightarrow$ & 4.12 & 3.66 & 0.66 \\
\hline AKI & $0.81(0.61,1.08)$ & $\rightarrow$ & 10.88 & 8.8 & 0.17 \\
\hline ARF & $0.73(0.56,0.95)$ & $\rightarrow$ & 13.81 & 10.04 & 0.02 \\
\hline
\end{tabular}

Figure 3 Forrest plot graph showing adjusted odds ratio for in-hospital outcomes after propensity score matching. Abbreviations: AKI, acute kidney injury; ARF, acute respiratory failure; C.I., confidence interval.

short-term and long-term outcomes. ${ }^{34-36}$ A lower level of serum cholesterol was found to be associated with the worse one-year outcomes in heart failure patients, ${ }^{37,38}$ and the mortality difference between the low cholesterol group and high cholesterol group can be appreciated after 30-day follow up..$^{39}$ Likewise, type-A acute aortic dissection patients with lower cholesterol levels have a higher in-hospital mortality as well. ${ }^{40}$

Postulated mechanisms of this phenomenon are as follows. First, sepsis, as the third leading cause of short-term ${ }^{41}$ and long-term ${ }^{42}$ cause of death in TCM, is accountable for $21.6 \%$ of inpatient mortality among patients with $\mathrm{TCM}^{41}$ Lipoproteins may downregulate the inflammatory immune response via interaction between lipoproteins and bacterial lipopolysaccharide (LPS) in sepsis, and LDL-C has been shown to bind LPS and to protect against the immediate toxic effects of LPS on endothelial cells. ${ }^{43}$ The higher level of lipoproteins in HLD patients may have a protective effect for sepsis which is a major cause of death in TCM.

In addition, with the use of statin as the first-line treatment of HLD, patients in HLD group most likely benefit from the statins' anti-inflammation effect. ${ }^{44}$ For example, atorvastatin, one of the most widely used statins, was found to decrease the expression of inflammatory factors, such as interleukin-6 (IL-6) ${ }^{45}$ which is associated with higher incidence of adverse event from TCM. ${ }^{46}$ Another retrospective study of 1617 myocardial infarction patients also found that long-term statins use was associated with lower C-reactive protein levels and better myocardial reperfusion. This antiinflammation benefit was independent of its lipid-lowering effect. ${ }^{47}$ Though a retrospective study by Dias et al involving 146 participants who received statin during hospitalization found that statins was not associated with major adverse cardiovascular events in TCM patients after multivariate analysis, ${ }^{14}$ only 96 of them had a history of HLD, and the statins were prescribed in an inpatient setting, which may not have been reflective of the long-term benefit of the statins. Patients with an established diagnosis of HLD are more likely to be on a statin chronically and may be able to benefit most from the anti-inflammatory effects, though more prospective study is warranted to verify this hypothesis.

Finally, compared to patients with HLD, those without HLD may include a subset of individuals with low cholesterol and TG levels. A previous study found that cholesterol level had a strong correlation with pre-albumin - a strong indicator of nutritional status. ${ }^{48}$ Data from National Health and Nutrition Examination Surveys has demonstrated that TG levels had a significant correlation with Body Mass Index, ${ }^{49}$ which is another common indicator of nutritional status. Therefore, we inferred that part of patients in nonHLD group to have low nutrition status in theory, though we could not obtain data on nutritional status (such as LDL-C, pre-albumin and weight) from the NIS database. Low cholesterol and TG level may reflect the state of malnutrition and cachexia - this may be one of the factors that resulted in worse outcomes for TCM patients without HLD.

The study has several strengths. First, given the rarity of TCM, we used the latest NIS from both 2016 and 2017 - the largest national inpatient database and 
identified 3139 patients. Second, we created an adjusted cohort with a balanced baseline characteristics and comorbidities by using propensity score matching. By doing so, we were able to minimize the confounding factors to determine a true correlation. Lastly, this is the first study to determine the correlation between HLD and the outcomes of patients admitted in hospital for TCM.

There are several limitations in our study. First, due to a retrospective nature of the study, we can only minimize confounding factors, not eliminate the confounding factors. In addition, the comorbidities were selected based on ICD-10CM codes, and the severity and duration of comorbidities could not be ascertained. Moreover, given the nature of NIS data, certain data on lipid levels (such as serum cholesterol, triglyceride level) and nutritional status (such as weight and pre-albumin levels) were not available, which prevents us from analyzing those factors. Similarly, treatment information (such as statin, non-steroidal anti-inflammatory drugs, steroids and anti-inflammatory agents) were not included in the NIS data. These details are important to determine the impact of lipid and lipid-lowering agents on TCM. Moreover, certain mechanical features of TCM, such as typical versus atypical, may play a role in the outcomes, but were again not available in the NIS.

\section{Conclusion}

We conclude that HLD is paradoxically associated with better in-hospital outcomes of TCM hospitalization. TCM patients with HLD have a lower in-hospital mortality rate, lower incidence of cardiogenic shock and ARF, shorter LOS and lower total charges of stay. Further studies are needed to investigate the factors and medical therapies that may contribute to reductions of in-hospital mortality in TCM patients with HLD. Moreover, a more complete understanding of the role of lipid metabolism in TCM patients may help guide treatment strategies and maximize the benefit of the effect of dyslipidemia treatment.

\section{Abbreviations}

ACS, acute coronary syndrome; AKI, acute kidney injury; ARF, acute respiratory failure; CHD, coronary heart diseases; CKD, chronic kidney disease; COPD, chronic obstructive pulmonary disease; DM, diabetes mellitus; Hippo-YAP/ZAP, Hippo Yes-associated protein/YLP motif contain 1; HLD, Hyperlipidemia; ICD-10-CM, the International Classification of Diseases, Tenth Revision, Clinical Modification; IL-6, interleukin-6; LDL-C, low-density lipoprotein cholesterol; LOS, length of stay; LPS, lipopolysaccharide; NIS, National Inpatient Sample; OSA, obstructive sleep apnea; ox-LDL, oxidized low-density lipoprotein cholesterol; PAD, peripheral artery disease; SD, standard deviation; TCM, takotsubo cardiomyopathy; TG, triglycerides.

\section{Acknowledgments}

The authors thank Daniel $\mathrm{Xu}$, A.B. for providing editorial support. Pengyang Li, MD and Xiaojia Lu, MD contributed equally to the writing of this article and share primary authorship.

\section{Funding}

This research was financially supported by $2020 \mathrm{Li} \mathrm{Ka}$ Shing Foundation Cross-Disciplinary Research Grant (L1111 2004) and Grant for Key Disciplinary Project of Clinical Medicine under the Guangdong High-level University Development Program (2020).

\section{Disclosure}

The authors report no conflicts of interest in this work.

\section{References}

1. Sato H. Tako-tsubo-like left ventricular dysfunction due to multivessel coronary spasm. In: Kodama K, Haze K, Hori M, editors. Clinical Aspect of Myocardial Injury: From Ischemia to Heart Failure. Tokyo: Kagakuhyoronsha Publishing Co; 1990:56-64; (Article in Japanese).

2. O'Rourke MF, Namasivayam M, Adji A. Takotsubo cardiomyopathy: an extreme in the cardiovascular continuum? J Hypertens. 2019;37 (3):501-503. doi:10.1097/HJH.0000000000001965

3. Ghadri J-R, Wittstein IS, Prasad A, et al. International expert consensus document on takotsubo syndrome (part II): diagnostic workup, outcome, and management. Eur Heart J. 2018;39(22):2047-2062. doi:10.1093/eurheartj/ehy077

4. Akashi YJ, Sakakibara M, Miyake F. Reversible left ventricular dysfunction "takotsubo" cardiomyopathy associated with pneumothorax. Heart. 2002;87(2):E1. doi:10.1136/heart.87.2.e1

5. Lyon AR, Rees PSC, Prasad S, Poole-Wilson PA, Harding SE. Stress (Takotsubo) cardiomyopathy-a novel pathophysiological hypothesis to explain catecholamine-induced acute myocardial stunning. Nat Clin Pract Cardiovasc Med. 2008;5(1):22-29. doi:10.1038/ncpcardio1066

6. Medina de Chazal H, Del Buono MG, Keyser-Marcus L, et al. Stress cardiomyopathy diagnosis and treatment: JACC state-of-the-art review. J Am Coll Cardiol. 2018;72(16):1955-1971. doi:10.1016/j.jacc.2018.07.072

7. Templin C, Napp LC, Ghadri JR. Takotsubo syndrome: underdiagnosed, underestimated, but understood? J Am Coll Cardiol. 2016;67 (16):1937-1940. doi:10.1016/j.jacc.2016.03.006

8. Templin C, Ghadri JR, Diekmann J, et al. Clinical features and outcomes of takotsubo (stress) cardiomyopathy. $N$ Engl J Med. 2015;373(10):929-938. doi:10.1056/NEJMoa1406761

9. Centers for Disease Control and Prevention (CDC). Vital signs: prevalence, treatment, and control of high levels of low-density lipoprotein cholesterol-United States, 1999-2002 and 2005-200. MMWR Morb Mortal Wkly Rep. 2011;60(4):109-114.

10. Borén J, Chapman MJ, Krauss RM, et al. Low-density lipoproteins cause atherosclerotic cardiovascular disease: pathophysiological, genetic, and therapeutic insights: a consensus statement from the European Atherosclerosis Society Consensus Panel. Eur Heart J. 2020 . 
11. Fan D, Li L, Li Z, et al. Effect of hyperlipidemia on the incidence of cardio-cerebrovascular events in patients with type 2 diabetes. Lipids Health Dis. 2018;17(1):102. doi:10.1186/s12944-018-0676-x

12. Summers MR, Lennon RJ, Prasad A. Pre-morbid psychiatric and cardiovascular diseases in apical ballooning syndrome (tako-tsubo/stressinduced cardiomyopathy): potential pre-disposing factors? $\mathrm{J} \mathrm{Am} \mathrm{Coll}$ Cardiol. 2010;55(7):700-701. doi:10.1016/j.jacc.2009.10.031

13. Opolski G, Pawlak MM, Roik MF, et al. Clinical presentation, treatment, and long-term outcomes in patients with takotsubo cardiomyopathy. Experience of a single cardiology center. Pol Arch Med Wewn. 2010;120(6):231-236.

14. Dias A, Franco E, Koshkelashvili N, et al. Antiplatelet therapy in Takotsubo cardiomyopathy: does it improve cardiovascular outcomes during index event? Heart Vessels. 2016;31(8):1285-1290. doi:10.1007/s00380-015-0729-2

15. Garg J, Krishnamoorthy P, Palaniswamy C, Pandey A, Ahmad H. Predictors of in-hospital mortality in coronary artery dissection: findings from the National Inpatient Sample 2009-2010. Cardiol J. 2015;22(2):135-140. doi:10.5603/CJ.a2014.0048

16. Reddy VS, Bui QT, Jacobs JR, Begelman SM, Miller DP, French WJ. Relationship between serum low-density lipoprotein cholesterol and in-hospital mortality following acute myocardial infarction (the lipid paradox). Am $J$ Cardiol. 2015;115(5):557-562. doi:10.1016/j. amjcard.2014.12.006

17. Horwich TB, Hernandez AF, Dai D, Yancy CW, Fonarow GC. Cholesterol levels and in-hospital mortality in patients with acute decompensated heart failure. Am Heart J. 2008;156(6):1170-1176. doi:10.1016/j.ahj.2008.07.004

18. Kim H, Senecal C, Lewis B, et al. Natural history and predictors of mortality of patients with Takotsubo syndrome. Int $J$ Cardiol. 2018;267:22-27. doi:10.1016/j.ijcard.2018.04.139

19. HCUP Nationwide Inpatient Sample (NIS), Healthcare Cost and Utilization Project (HCUP). Agency for healthcare research and quality. Rockville, MD. Available from: https://www.hcup-us.ahrq. gov/nisoverview.jsp. Accessed August 27, 2020.

20. Southern DA, Norris CM, Quan H, et al. An administrative data merging solution for dealing with missing data in a clinical registry: adaptation from ICD-9 to ICD-10. BMC Med Res Methodol. 2008;8:1. doi:10.1186/1471-2288-8-1

21. Manfredini R, Fabbian F, Giorgi AD, et al. Heart and lung, a dangerous liaison-Tako-tsubo cardiomyopathy and respiratory diseases: a systematic review. World J Cardiol. 2014;6(5):338-344. doi:10.4330/wjc.v6.i5.338

22. Li P, Lu X, Teng C, et al. The impact of COPD on in-hospital outcomes in patients with takotsubo cardiomyopathy. Int J Chron Obstruct Pulmon Dis. 2020;15:2333-2341. doi:10.2147/COPD.S267289

23. Lazzeroni D, Bini M, Castiglioni P, et al. Anxiety disorders and stressful events in Takotsubo syndrome. Cardiol J. 2018;25 (4):495-500. doi:10.5603/CJ.a2017.0136

24. Zalewska-Adamiec M, Malyszko J, Bachórzewska-Gajewska H, Tomaszuk-Kazberuk A, Dobrzycki SJ. Takotsubo syndrome - fatal prognosis of patients with low body mass index in 5-year follow-up. Arch Med Sci. 2020;16(2):282-288. doi:10.5114/aoms.2019.87082

25. Stiermaier T, Santoro F, El-Battrawy I, et al. Prevalence and prognostic impact of diabetes in takotsubo syndrome: insights from the international, multicenter GEIST registry. Diabetes Care. 2018;41 (5):1084-1088. doi:10.2337/dc17-2609

26. Yassin AS, Adegbala O, Subahi A, et al. Clinical impact of advanced chronic kidney disease on outcomes and in-hospital complications of Takotsubo syndrome (broken-heart-syndrome): propensity-matched national study. Int $J$ Cardiol. 2019;277:16-19. doi:10.1016/j. ijcard.2018.09.098

27. Vallabhajosyula S, Deshmukh AJ, Kashani K, Prasad A, Sakhuja A. Tako-tsubo cardiomyopathy in severe sepsis: nationwide trends, predictors, and outcomes. J Am Heart Assoc. 2018;7(18):e009160. doi:10.1161/JAHA.118.009160
28. Stuart EA, Lee BK, Leacy FP. Prognostic score-based balance measures can be a useful diagnostic for propensity score methods in comparative effectiveness research. J Clin Epidemiol. 2013;66(8): S84-S90.e1. doi:10.1016/j.jclinepi.2013.01.013

29. Naegele M, Flammer AJ, Enseleit F, et al. Endothelial function and sympathetic nervous system activity in patients with Takotsubo syndrome. Int $J$ Cardiol. 2016;224:226-230. doi:10.1016/j. ijcard.2016.09.008

30. Uchida Y, Egami H, Uchida Y, et al. Possible participation of endothelial cell apoptosis of coronary microvessels in the genesis of Takotsubo cardiomyopathy. Clin Cardiol. 2010;33(6):371-377. doi:10.1002/clc. 20777

31. Hu J, Liu T, Zhang Z, Xu Y, Zhu F. Oxidized low-density lipoprotein promotes vascular endothelial cell dysfunction by stimulating miR-496 expression and inhibiting the hippo pathway effector YAP. Cell Biol Int. 2019;43(5):528-538. doi:10.1002/cbin.11120

32. Muller C, Salvayre R, Nègre-Salvayre A, Vindis C. HDLs inhibit endoplasmic reticulum stress and autophagic response induced by oxidized LDLs. Cell Death Differ. 2011;18(5):817-828. doi:10.1038/cdd.2010.149

33. Jacobs M, Plane F, Bruckdorfer KR. Native and oxidized low-density lipoproteins have different inhibitory effects on endothelium-derived relaxing factor in the rabbit aorta. $B r J$ Pharmacol. 1990;100 (1):21-26. doi:10.1111/j.1476-5381.1990.tb12045.x

34. Cheng K-H, Chu C-S, Lin T-H, Lee K-T, Sheu S-H, Lai W-T. Lipid paradox in acute myocardial infarction-the association with 30-day in-hospital mortality. Crit Care Med. 2015;43(6):1255-1264. doi:10.1097/CCM.0000000000000946

35. Martin SS, Faridi KF, Joshi PH, et al. Remnant lipoprotein cholesterol and mortality after acute myocardial infarction: further evidence for a hypercholesterolemia paradox from the TRIUMPH registry. Clin Cardiol. 2015;38(11):660-667. doi:10.1002/clc.22470

36. Xia T-L, Li Y-M, Huang F-Y, et al. The triglyceride paradox in the mortality of coronary artery disease. Lipids Health Dis. 2019;18 (1):21. doi:10.1186/s12944-019-0972-0

37. Horwich TB, Hamilton MA, Maclellan WR, Fonarow GC. Low serum total cholesterol is associated with marked increase in mortality in advanced heart failure. J Card Fail. 2002;8(4):216-224. doi:10.1054/jcaf.2002.0804216

38. Rauchhaus M, Clark AL, Doehner W, et al. The relationship between cholesterol and survival in patients with chronic heart failure. $J \mathrm{Am}$ Coll Cardiol. 2003;42(11):1933-1940. doi:10.1016/j.jacc.2003.0 7.016

39. Afsarmanesh N, Horwich TB, Fonarow GC. Total cholesterol levels and mortality risk in nonischemic systolic heart failure. Am Heart J. 2006;152(6):1077-1083. doi:10.1016/j.ahj.2006.06.015

40. Liu X, Su X, Zeng H. Impact of admission serum total cholesterol level on in-hospital mortality in patients with acute aortic dissection. Pak J Med Sci. 2016;32(4):939-943. doi:10.12669/pjms.324.10124

41. Brinjikji W, El-Sayed AM, Salka S. In-hospital mortality among patients with takotsubo cardiomyopathy: a study of the national inpatient sample 2008 to 2009. Am Heart J. 2012;164(2):215-221. doi:10.1016/j.ahj.2012.04.010

42. Sharkey SW, Pink VR, Lesser JR, Garberich RF, Maron MS, Maron BJ. Clinical profile of patients with high-risk tako-tsubo cardiomyopathy. Am J Cardiol. 2015;116(5):765-772. doi:10.1016/j. amjcard.2015.05.054

43. Van Lenten BJ, Fogelman AM, Haberland ME, Edwards PA. The role of lipoproteins and receptor-mediated endocytosis in the transport of bacterial lipopolysaccharide. Proc Natl Acad Sci USA. 1986;83 (8):2704-2708. doi:10.1073/pnas.83.8.2704

44. Yoon SS, Dillon CF, Carroll M, Illoh K, Ostchega Y. Effects of statins on serum inflammatory markers: the U.S. National Health and Nutrition Examination Survey 1999-2004. J Atheroscler Thromb. 2010;17(11):1176-1182. doi:10.5551/jat.5652 
45. Tousoulis D, Antoniades C, Vasiliadou C, et al. Effects of atorvastatin and vitamin $\mathrm{C}$ on forearm hyperaemic blood flow, asymmentrical dimethylarginine levels and the inflammatory process in patients with type 2 diabetes mellitus. Heart. 2007;93(2):244-246. doi:10.1136/hrt.2006.093112

46. Santoro F, Tarantino N, Ferraretti A, et al. Serum interleukin 6 and 10 levels in Takotsubo cardiomyopathy: increased admission levels may predict adverse events at follow-up. Atherosclerosis. 2016;254:28-34. doi:10.1016/j.atherosclerosis.2016.09.012

47. Oduncu V, Tanalp AC, Erkol A, et al. Impact of chronic pre-treatment of statins on the level of systemic inflammation and myocardial perfusion in patients undergoing primary angioplasty. Am J Cardiol. 2011;107(2):179-185. doi:10.1016/j.amjcard.2010.09.008
48. Araújo JP, Friões F, Azevedo A, et al. Cholesterol-a marker of nutritional status in mild to moderate heart failure. Int $J$ Cardiol. 2008;129(1):65-68. doi:10.1016/j.ijcard.2007.05.026

49. Ford ES, Li C, Zhao G, Pearson WS, Mokdad AH. Hypertriglyceridemia and its pharmacologic treatment among US adults. Arch Intern Med. 2009;169(6):572-578. doi:10.1001/ archinternmed.2008.599

Diabetes, Metabolic Syndrome and Obesity: Targets and Therapy

\section{Publish your work in this journal}

Diabetes, Metabolic Syndrome and Obesity: Targets and Therapy is an international, peer-reviewed open-access journal committed to the rapid publication of the latest laboratory and clinical findings in the fields of diabetes, metabolic syndrome and obesity research. Original research, review, case reports, hypothesis formation, expert opinion and commentaries are all considered for publication. The manuscript management system is completely online and includes a very quick and fair peer-review system, which is all easy to use. Visit http://www.dovepress.com/testimonials.php to read real quotes from published authors. 